\title{
Beam Dynamics Studies of Four-gap Low-beta Superconducting Resonators
}

\author{
J. A. Nolen and K. Joh \\ Argonne National Laboratory \\ Argonne, IL 60439, U. S. A.
}

\section{Abstract}

The four-gap superconducting resonators which have been developed at Argonne for use in the low-heta positive ioninjector for ATLAS [1] have potential applications for ions with velocities less than $0.007 \mathrm{c}$ and $q / m$ less than 0.1 . It was previously observed that at low velocities these structures can be focussing in both longitudinal and transverue phase spaces due to an inherent alternating-phasefocussing property [2]. Studies are underway to determine the optimum combination of multi-gap structures and solenoids at low velocity and low $\mathrm{q} / \mathrm{m}$. In this paper we present the results of acceptance studies for the first three resonators at the front of the positive-ion injector linac, with and without the focusaing solenoids. These studies include the effects of higher-order distortions in longitndinal and transverse phase spaces since minimising such aberrations is very important for most nuclear physics applications of such accelerators.

\section{INTRODUCTION}

The new positive-ion injector (PII) linac for ATLAS uses 18 4-gap superconducting niobium resonators [1] to accelerate ions as heavy as uranium from initial velocities of about $0.008 \mathrm{c}$ [3] [4]. The succesoful performance of this new linac has led us to inventigate possible extensions of this technology to even lower velocities, with potential applications in the acceleration of radioactive beams. We are first investigating the details of the beam dynamics at the low velocity end of this linac, with special emphasis on the transverse and longitudinal acceptances and nonlinearities. (see paper Ga9 of this conference [5].) Figure 1 is a schematic of the first two types of resonator at the entrance of the PII linac.
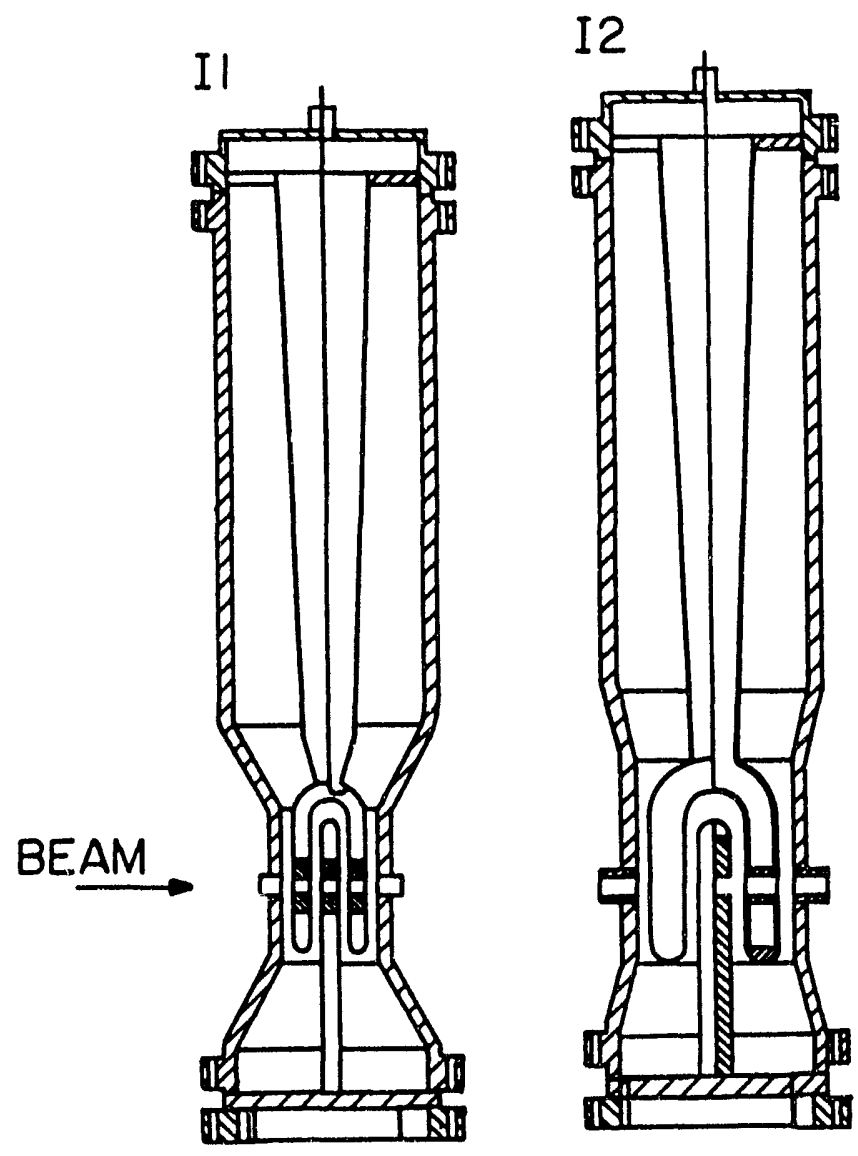

Figure 1: The first two of the four types of superconducting resonators in the PII linac; they are $48.5 \mathrm{MH}$. quarter-wave atructures. The II type (left) has an effective length of $10 \mathrm{~cm}$, in which the beam energy more than doubles.

\section{DISCLAIMER}

This report was prepared as an account of work sponsored by an agency of the United States Government. Neither the United States Government nor any agency thereof, nor any of their employees, makes any warranty, express or implied, or assumes any legal liability or responsibility for the accuracy, completeness, or usefulness of any information, apparatus, product, or process disclosed, or represents that its use would not infringe privately owned rights. Reference herein to any specific commercial proiuct, process, or service by trade name, trademark, manufacturer, or otherwise does not necessarily constitute or imply its endorsement, recommendation, or favoring by the United States Government or any agency thereof. The views and opinions of authors expressed herein do not necessarily state or reflect those of the United States Government or any agency thereof.

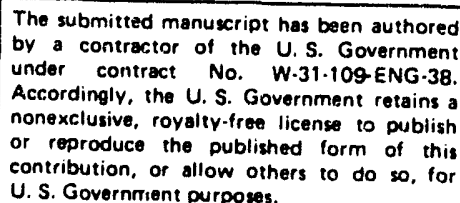




\section{Alternating-Phase Focussing}

Due to the rapid velocity increase in the first few gaps of this linac, as shown in Figure 2, there is an inherent alternating-phase focussing aspect to the beam dynamica [2] [6]. Figure 3 illustrates that the transverse focussing for an argon beam is so strong that an initially diverging beam is brought to a waist within the first $10 \mathrm{~cm}$. Figures 4 and 5 illustrate more schematically the transverse and longitudinal focussing properties of the first two resonators for both argon and uranium beams.
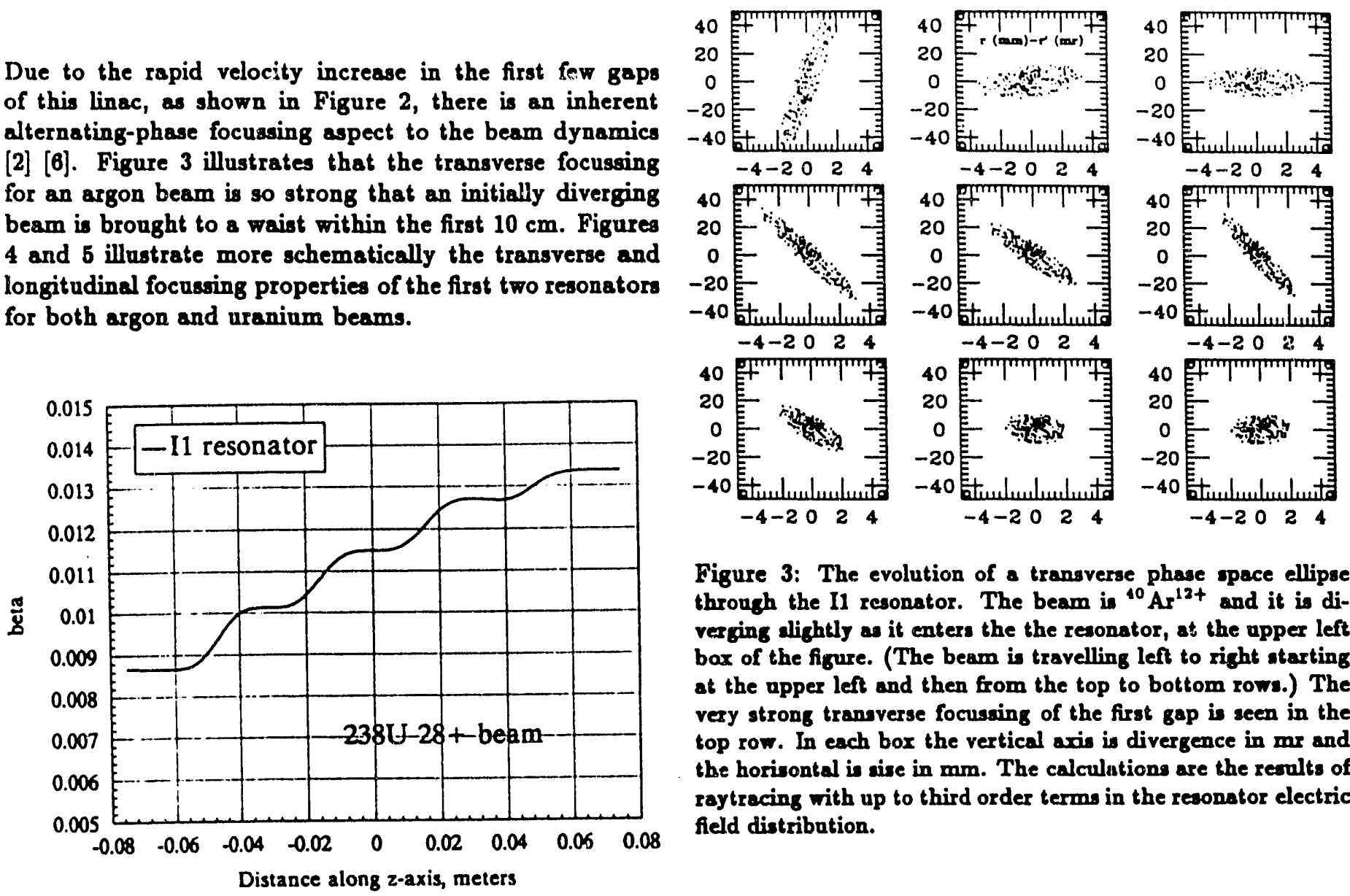

Figure 3: The evolution of a transverse phase space ellipse through the I1 resonator. The beam is ${ }^{10} \mathrm{Ar}^{12+}$ and it is diverging alightly as it enters the the resonator, at the upper left bax of the figure. (The beam is travelling left to right atarting at the upper left and then from the top to bottom rows.) The very strong transverse focussing of the first gap in seen in the top row. In each box the vertical axis is divergence in mx and the horisontal is aise in $\mathrm{mm}$. The calculations are the results of raytracing with up to third order terms in the resonator electric field distribution.

Figure 2: The velocity, beta, of a uranium beam entering the I1 resonator at about $0.0086 \mathrm{c}$ and leaving at about $0.0134 \mathrm{c}$. The gradient is $4.5 \mathrm{MV} / \mathrm{m}$ over the $10 \mathrm{~cm}$ effective leng,th of the cavity.

\section{NONLINEARITIES}

The low velocity end of the PII linac consists of the following components: solenoid, I1 resonator, solenoid, I2 resonator, solenoid, second 12 resonator, etc. We have done calculations to compare the acceptances of the linac, in longitudinal and transverse phase spaces, for this standard configuration and for the case with the first three superconducting solenoids turned off. "Geometrical" and "Linear" acceptances were evaluated [5]. Although the acceptances are significantly greater with the solenoids, the results without look promising enough to search for more optimum configurations. Since the present calculations
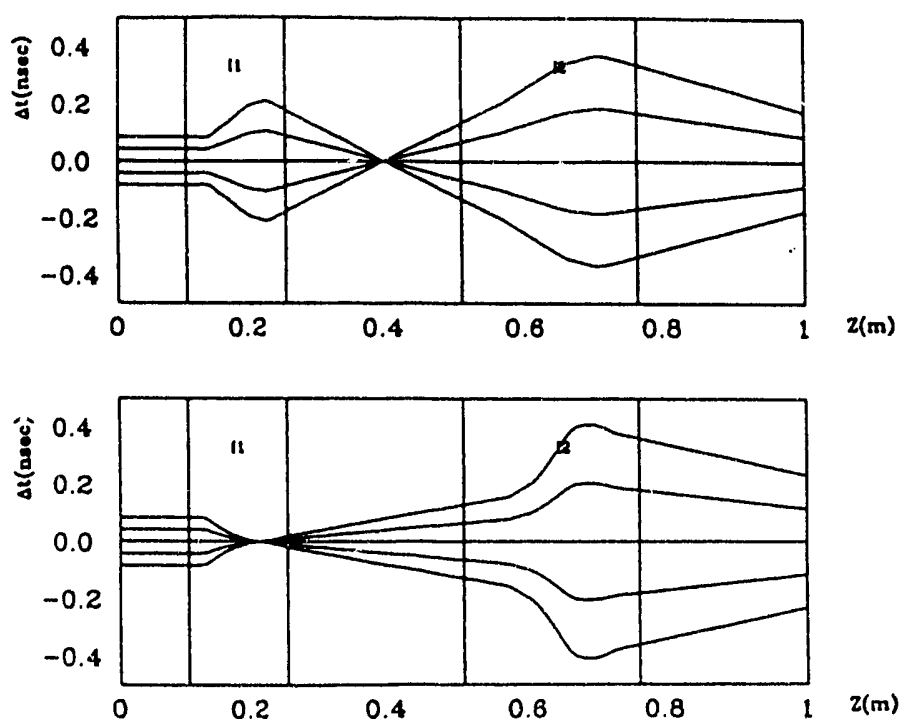

Figure 4: Raytracing of initially parallel trajectories through I1 and I2. The upper plot is for a ${ }^{40} \mathrm{Ar}^{12+}$ beam, and the lower is for a ${ }^{238} \mathrm{U}^{24+}$ beam. In this case the vertical axis is the time deviation from the central partical. In both cases the if phases are set for longitudinal focussing. 

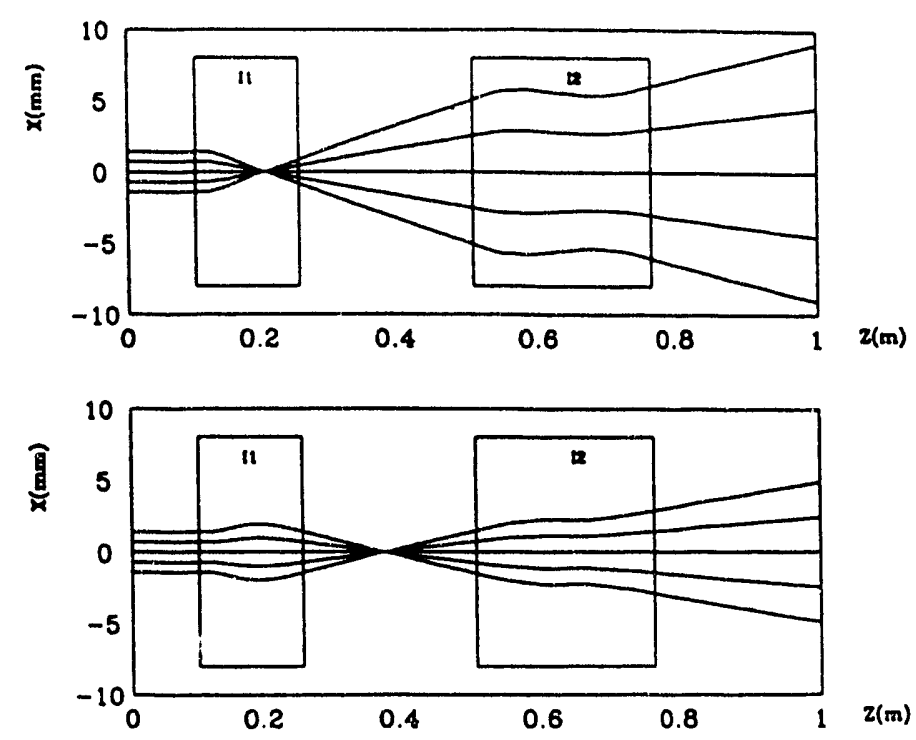

Figure 5: Plots aimilar to Figure 4, but in transverse phase space. The I1 resonator is stongly focuaning for both beams, while I2 is only alighly focusaing.

have been done with the actual linac configuration, it will be straightforward to test these predictions with actual beams in the near future. Figure 6 shows the predicted degree of distortion after three resonators for a uranium beam with no transverse focusaing between them.

\section{Future Studies}

These studies will be continued, to develope the optimum combination of resonators and transverse focussing elements. Experimental studies will be done to test the predictions. As we gain experience with and understanding of the dynamics of these linac structures, more cost effective solutions will almost certainly evolve. For the first stages of acceleration of radioactive beams structures capable of accelerating ions with $\mathrm{q} / \mathrm{m}$ values much less than the present 0.1 will be necessary. It appears that the PII technology will also be useful in this lower velocity, lower q/m regime.

This work was supported in part by the U.S. Department of Energy, Nucl. Phys. Div, under contract No. W-31-109ENG-38
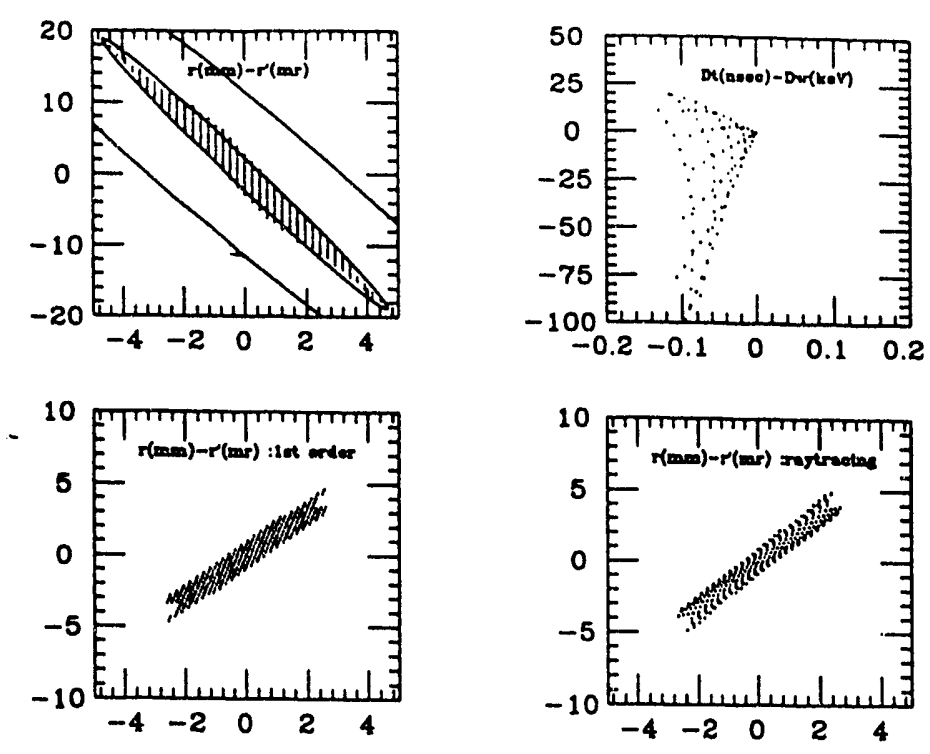

Figure 6: The shaded ellipse in the upper left box represents a tranoverse area of $11 \pi \mathrm{mm} \cdot \mathrm{mr}$ for a uranium beam entering the Il resonator. The lower right box shows the particles tranamitted, as calculated via raytracing. The lower left box ahows the same particles calculated to first order only. The upper right ahow the amount of emittance growth in the longitudinal coordinates in keV vertical axis and nsec horisontal axis. The initial longitudinal emittance was assumed to be sero to illustrate the coupling terms.

\section{REFERENCES}

[1] K.W. Shepard, et al., Proc. 1989 IEEE Part. Accel. Conf., IEEE\#89CH2669-0(1987)974.

[2] R.C. Pardo, et al., Proc. 1987 IEEE Part. Accel. Conf., IEEE\#87CH2387-9(1987)1228.

[3] R.C. Pardo, et al., paper Mc8 at this conference.

[4] L.M. Bollinger et al., Nuclear Physics, A553, (1993) 859c-862c.

[b] K. Joh and J.A. Nolen, paper Ga9 at this conference.

[6] L. Sagalovsky and J.R. Delayen, Proc. 1992 Linear Accel. Conf., C.R. Hoffmann, Ed., AECL10728(1992)763. 

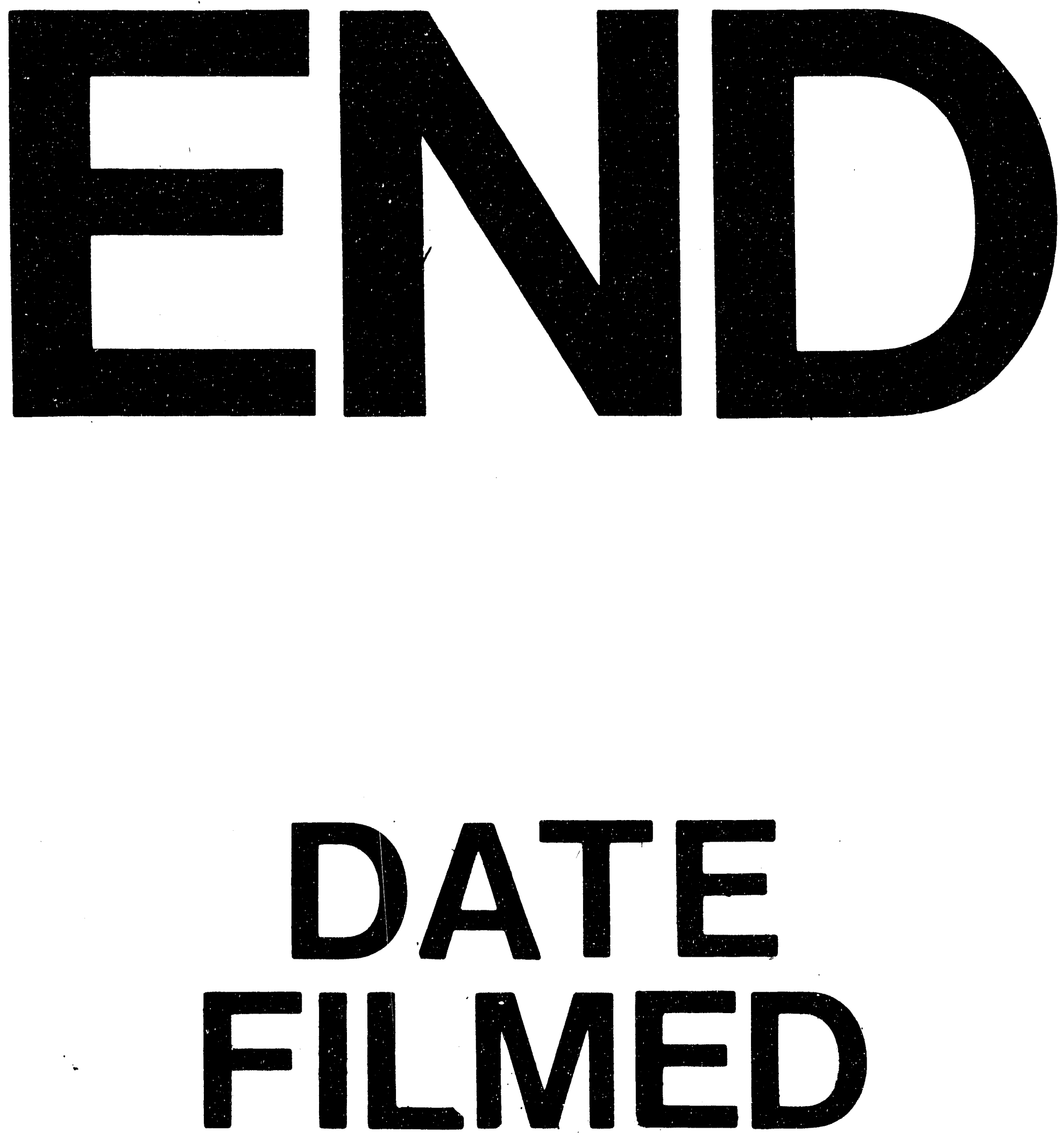

1

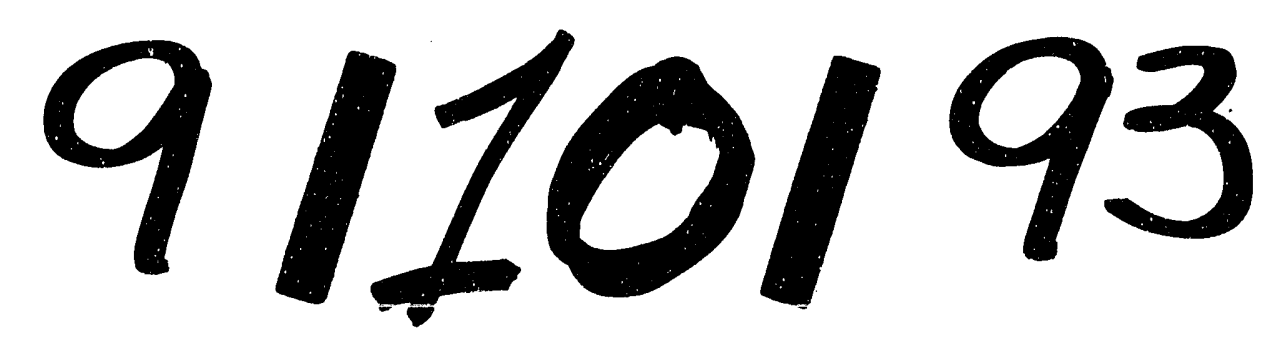


